\title{
POLLEN MORPHOLOGY OF THE GENUS ALNUS MILL. IN HYRCANIAN FORESTS, NORTH OF IRAN
}

\author{
SHAYANMEHR, F. ${ }^{1}-$ JALALI, S.GH. ${ }^{1}-$ HOSSEINZADEH COLAGAR, A. $.^{2^{*}}-$ \\ YOUSEFZADEH, $\mathrm{H}^{1}{ }^{1}$ ZARE, $\mathrm{H}^{3}$ \\ ${ }^{I}$ Forestry Department of Tarbiat Modares University, Nour, Mazandaran province, Iran. \\ ${ }^{2}$ Department of Molecular and Cell Biology, University of Mazandaran, Mazandaran province, \\ Iran. 3Agricultural and Natural Resources Center of Mazandaran, Nowshahr, \\ Mazandaran province, Iran. \\ (phone: +98-122-6253101; fax: +98-122-6253499) \\ *Corresponding author \\ e-mail:acolagar@yahoo.com,ahcolagar@umz.ac.ir \\ (Received $1^{\text {st }}$ Nov 2013; accepted $14^{\text {th }}$ Apr 2014)
}

\begin{abstract}
This study evaluated and compared the morphological characteristics of the pollen grains in the different taxa of the genus Alnus in Hyrcanian forests, north of Iran. The pollen characteristics of five new taxa of the genus Alnus were studied and compared in these forests for the first time. The male catkins from 84 alder individuals of 25 populations were collected throughout the Hyrcanian forests and then recognized and grouped in the eight taxa. After extraction and washing with the standard method of the acetolysis procedure, pollen grains were photographed using light and electron microscopy imaging. Their morphological characteristics were measured afterwards. Alder pollen shape was oblate, with 3 to 6 pores: $1.2 \%$ triporate, $42.2 \%$ tetraporate, pantoporate $53 \%, 6 / 3 \%$ hexaporate. The aperture type also was annulate or annulus. About 10.8\% of the grains were classified in small size (less than $25 \mu \mathrm{m}$ ) and the rest were in average size $(25-50 \mu \mathrm{m})$. The large diameter of the investigated pollen varied from 20.7 to 39.3 micron $($ mean $=29.5 \mu \mathrm{m})$ and the small diameter from 19.8 to 36.7 micron $($ mean $=28.5 \mu \mathrm{m})$. About $36 \%$ of the pollen grains were concave, $37.2 \%$ mixed and $26.8 \%$ also convex based on wall shape. Cluster analysis based on the quantitative traits of pollen grains grouped altogether taxa in single cluster and none of taxa were categorized into separate cluster. Discriminante analysis based on six quantitative pollen traits showed high similarity and overlap among different alder taxa. Totally, it was found that eight alder taxa have shown little divergence in terms of pollen morphological characteristics, and consequently determining the limitation of these taxa could not easily practicable.
\end{abstract}

Keywords: alder tree, pollen grain, exine ornamentation, oblate, SEM

\section{Introduction}

The genus Alnus Mill. is one of six genera of Betulaceae and the only member of this family that has the ability to fix nitrogen through symbiosis relationship with soil filamentous bacteria called Frankia (Benson and Silvester, 1993; Chen et al., 1999; Chen and $\mathrm{Li}, 2004)$. Alder species widely distributed in temperate regions of northern hemisphere, with the exception of Alnus glutinosa (L.) which disperses also throughout the Andes, and small parts of North Africa (Benson and Silvester, 1993; Chen et al., 1999). Since most of alders live in river sides and marsh environments, they fall later than the other tree species. They are generally monoecious plants with the wind pollinated flowers. The pollens positioned into cylindrical male catkins in reddish colored with the length of $10.5 \mathrm{~cm}$ and will change to yellow, after they ripened in the fall (Chen et al., 1999).

Alder species has high potential to generating subspecies and hybrids because of the sympatric distribution of this genus (Ren et al., 2010; King and Ferris, 2000). That 
means that the populations of the species are mixed together as a result of relatively similar biological and ecological needs (King and Ferris, 2000); Thus, the formation of species, subspecies or hybrids is found in the distribution area of the genus (Ren et al., 2010; King and Ferris, 2000) creating uncertainties in the classification of the genus Alnus (Ren et al., 2010).

Based on phylogenetic studies using molecular and morphological data, number of Alnus species have already mentioned about 29-35 in the universe that Asia had the largest contribution (23-18 species) (Murai, 1964; Furlow, 1979; Ashburner, 1986; Chen and Li, 2004; Chen et al., 1999). However, according to the latest data provided by the plant list database, a total of 62 taxa is presented and confirmed of which 44 are considered as species (The Plant list, 2010).

In flora Iranica (Browičs, 1972), a subspecies of the black alder called Alnus glutinosa ssp. barbata C. A. Mey. with two varieties of Caucasian alder namely $A$. subcordata var. subcordata C. A. Mey. and A. subcordata var. villosa (Regel) H.J.P.Winkl have been formerly recorded.

But based on new morphological research the number of 8 taxa have been noted for the genus Alnus of Iran (Zare and Amini, 2012). The presence of the two other subspecies of black alder namely A. glutinosa ssp. glutinosa (L.) Gaertn and A. glutinosa ssp. antitaurica Yalt. had previously been reported in flora of Turkey mentioned also in Hyrcanian forests of Iran (Zare and Amini, 2012). According to the recent study, another species of alder which is native to the Mediterranean regions called A. orientalis Decne. has been also reported in Iran by Zare and Amini (2012). Moreover, two new species of Alnus was recorded as A. dolichocarpa Zare, Amini and Assadi, and A. djavanshirii Zare (Zare and Amini, 2012).

Pollen morphological characteristics have been widely used to facilitate the classification of some plants and investigation of the complications existing among them. For example, the evaluation of quantitative and qualitative characteristics of pollen grains was very useful for the classification of the genus Picea (Lindbladh et al., 2002), Artemisia (Lin et al., 2005), Lamiaceae (Hong, 2007), Rosaceae (Chung et al., 2010), Petrorhagia (Aktaş et al., 2010), Cactaceae (Aguilar-García et al., 2012), Annonaceae (Doyle and Thomas, 2012), Agavoideae (Lopes et al., 2013), etc..

Due to much confusion about the taxonomy of the genus Alnus and recent studies as well, the micromorphological features of the mentioned species is still unknown in Iran. Therefore, the purpose of the current study is investigation of micromorphological characteristics of pollen grains of Alnus taxa in Iran using light and electron microscopy. This study tries to assess the efficiency of micromorphological characteristics of pollen in the genus Alnus taxa with applying multivariate statistical tests.

\section{Material and methods}

Pollen samples were collected from 84 alder individuals of 25 separate populations throughout Hyrcanian Forests in fall 2011. Individuals were sampled from West to East, including Anzali, Siyahkal, Deilaman, Lahijan, Roudsar, Ramsar, Noushahr Sangdeh, Veysar, Galandroud, Peimoud, Nour, Veresk, Touskacheshmeh, Zarringol valley, Neharkhoran, Ziarat valley, Touskestan, Ramiyan valley, Minoodasht, Sasng, Loveh and Golestan national park. Furthermore, the pollens collected from the herbarium samples of Noushahr, Kelarabad, Fooman (Abrod village) and Sangdeh were used. 
Furthermore, perfect herbarium samples collected from each individual (containing leaves and female cones) were identified in the Botanical Garden of Noushahr by botanists and experts. Collected Male catkins were prepared using standard method of acetolysis (Erdtman method) and studied by light microscope (Erdtman 1960; Bennett and Willis, 2001; Aguilar-García et al., 2012). In this procedure, the pollen bags were removed by first rubbing down the male catkins mechanically and then high speed centrifuging with acetic acid. The acetolysis solution (1 to 9 ratio of sulfuric acid and anhydride acetic acid) was added to them and then put in a hot water bath were centrifuged again twice. Finally, they were centrifuged and washed with ethanol and distilled water in two phases. In this method, the outer layer of pollen (Exine) will be cleared of external pollutants and quite pellucid and bright due to the effects of the acids (Erdtman 1960; Aguilar-García et al., 2012). Pollen grains then mixed with glycerol gels and were photographed under a light microscope. Micromorphological characteristics of pollen grains, measured based on validated descriptive methods (Furlow, 1979; Kapp et al., 2000; Blackmore et al., 2003; May and Lacourse, 2012).

Six quantitative morphological traits were measured for each pollen grain. These characteristics were: pollen large and small diameter, annulus width, annulus height, arci width and exine thickness (Furlow, 1979; Kapp et al., 2000; Blackmore et al., 2003; May and Lacourse, 2012).

In order to ensure accurate measurements, several time measurements was applied for each traits and then mean value was recorded (May and Lacourse, 2012). To assess the pollen large and small diameter, all diameters of grains were determined and the smallest and the largest values were selected. Figure 1 shows the pattern by which the quantitative traits of a triporate pollen is measured.

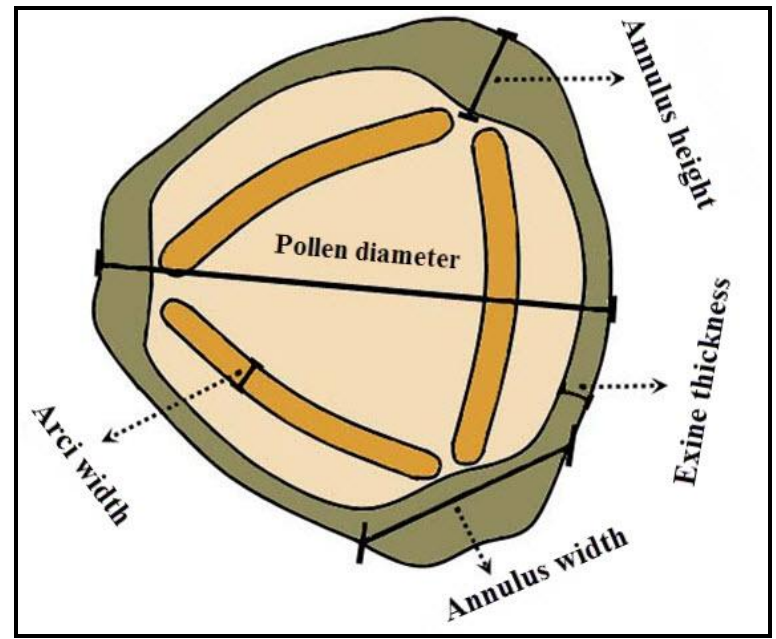

Figure 1. Measuring quantitative morphological traits in a triporate pollen

Moreover, two qualitative morphological traits evaluated: pollen shape and annulus protrusion. Besides, the number of pollen pores was counted for each grain separately. Pollen wall shape was classified to three convex, concave and mixed types (May and Lacourse, 2012). The measurements were conducted based on 20 pollen grains of each sample. However, 80 pollen grains of each sample were surveyed in order to estimate the number and percentage of quantitative traits. A total of 4,500 pollen grains were reviewed in this study. 
For imaging electron microscopy, washed pollen (based on acetolysis method), were attached using double-sided adhesive strip from the wall of falcon (pollen container), on the surface of aluminum stubs, and then placed into the sputter coater (BAL-TEC Swiss company model SCDOOS). The samples were then coated with a thin layer of gold and put up the chamber of SEM (Philips Netherland-Model XL30) and photographed (2500 to $5100 \mathrm{x}, 20 \mathrm{KV}$ ).

The samples of all the individuals were grouped in the eight-taxon after identification. First, the total number of clusters determined based on all attributes using the two-step cluster analysis and similarity of taxa were considered. The discriminant analysis was used to evaluate the accuracy of the allocation of tree individuals into composed clusters by stepwise method. The importance of the six quantitative characteristics of alder's pollen, in order to distinguish 8 taxa was determined by current test.

Pollen morphological characteristics measured using Zeiss AxioVision 4.8 software and ImageTools 3.0 with the accuracy of $0.02 \mu \mathrm{m}$. Adobe Photoshop 7.0 and Snagit Editor 11.0 software were used to edit and improve the quality of the images.

All measurements were under the Isopolar view of (seeing from polar axis) the pollens.

\section{Results}

The results showed that the classification of the genus Alnus based on the pollen shape is consider as oblate (The polar axis pollen is shorter than its equatorial one) from equatorial view. They were triporate to hexaporate. Aperture type of grains was annulate (annulus). Alder pollen is psilate it means there is no exine ornamentation under a standard light microscope. However, the electron microscopic images showed that the pollen surfaces were partly coarse and therefore classified as granulate-regulate in terms of exine ornamentation (Hesse et al., 2009; Blackmore et al., 2003).

Pollen classification was conducted based on dimensions by methods of Erdtman (1986) and Hesse et al (2009). About $10.8 \%$ of pollen grains had small size (less than $25 \mu \mathrm{m})$ and the other had medium size $(25-50 \mu \mathrm{m})$. The large diameter of the alder pollen varied from 20.7 to 39.3 micron (mean=29.5 $\mu \mathrm{m}$ ) and the small diameter from 19.8 to 36.7 micron $($ mean $=28.5 \mu \mathrm{m})$. Pollen annulus width ranged from 6.5 to 12.8 micron $($ mean $=9.7 \mu \mathrm{m})$ and the annulus height from 1.66 to 5.33 micron (mean $=3.38 \mu \mathrm{m})$.

Arci width had changes from 1.54 to 4.83 micron (mean=3.17 $\mu \mathrm{m}$ ) and the exine thickness from 1.28 to 2.67 micron (mean=1.86 $\mu \mathrm{m}$ ). About $36 \%$ of pollens were concave, $37.2 \%$ mixed and $26.8 \%$ convex in terms of pollen wall shape. Approximately 1.2 percent of the genus Alnus pollens were triporate, $42.2 \%$ tetraporate, $53 \%$ pantoporate and $3.6 \%$ hexaporate.

Table 1 shows the mean values of quantitative and qualitative morphological characteristics in eight separate taxa of Alnus.

Figure 2 shows box plots related to the six quantitative measured traits of pollens of the Hyrcanian alders. Box plots show inter- and intraspesific variation and also overlaps among eight taxa. The solid dark lines bisecting each box plot represent the trait median. Bottom and top border lines of boxes represent the first and third quartiles respectively. 
Table 1. Mean ( \pm standard error) values of quantitative and qualitative characteristics of each 8 taxa of Alnus

\begin{tabular}{|c|c|c|c|c|c|c|c|c|}
\hline $\begin{array}{c}\text { Pollen morphological } \\
\text { characteristics }\end{array}$ & 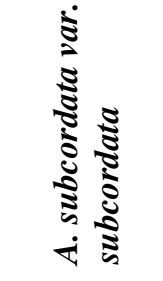 & 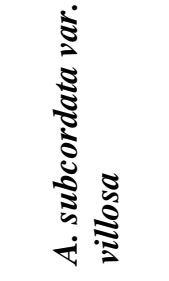 & 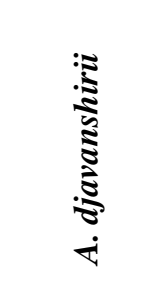 & 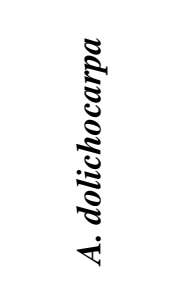 & 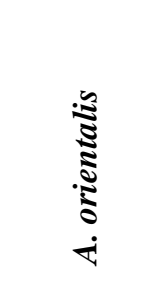 & 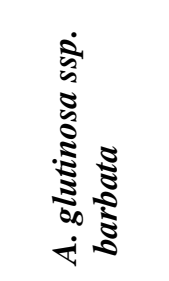 & 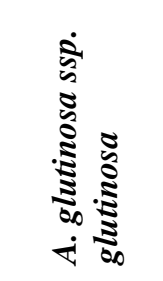 & 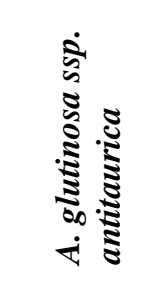 \\
\hline Large diameter $(\mu \mathrm{m})$ & $29.4 \pm 0.52$ & $28.9 \pm 0.70$ & $32.5 \pm 0.37$ & $33.2 \pm 0.55$ & $27.7 \pm 0.10$ & $26.1 \pm 1.02$ & $30.5 \pm 1.23$ & $28.3 \pm 0.59$ \\
\hline Small diameter $(\mu \mathrm{m})$ & $28.5 \pm 0.53$ & $27.8 \pm 0.70$ & $31.8 \pm 0.52$ & $32.2 \pm 0.69$ & $27.2 \pm 0.28$ & $25 \pm 1.02$ & $29.5 \pm 1.25$ & $27.2 \pm 0.68$ \\
\hline Annulus width $(\mu \mathrm{m})$ & $9.8 \pm 0.21$ & $9.4 \pm 0.26$ & $10.1 \pm 0.05$ & $11.3 \pm 0.06$ & $9.2 \pm 0.32$ & $8.7 \pm 0.22$ & $9.7 \pm 0.65$ & $9 \pm 0.28$ \\
\hline Annulus height $(\mu \mathrm{m})$ & $3.5 \pm 0.07$ & $3.4 \pm 0.11$ & $3.9 \pm 0.05$ & $4 \pm 0.05$ & $3.3 \pm 0.11$ & $3.2 \pm 0.12$ & $3.2 \pm 0.56$ & $3.3 \pm 0.07$ \\
\hline Arci width $(\mu \mathrm{m})$ & $3 \pm 0.09$ & $3.2 \pm 0.12$ & $3.8 \pm 0.02$ & $3.6 \pm 0.05$ & $3.1 \pm 0.35$ & $2.6 \pm 0.18$ & $2.9 \pm 0.05$ & $2.7 \pm 0.18$ \\
\hline Exine thicknes $(\mu \mathrm{m})$ & $1.9 \pm 0.05$ & $1.8 \pm 0.04$ & $2.1 \pm 0.01$ & $2.3 \pm 0.03$ & $2 \pm 0.14$ & $1.7 \pm 0.06$ & $1.9 \pm 0.10$ & $1.8 \pm 0.09$ \\
\hline \multicolumn{9}{|l|}{ Number of pores $(\%)$} \\
\hline Triporate & 3.7 & 0.6 & 0 & 2.3 & 0 & 0.8 & 0 & 0.4 \\
\hline Tetraporate & 48.4 & 44.6 & 18.8 & 44.2 & 44 & 27.7 & 66.5 & 19.3 \\
\hline Pantoporate & 44.7 & 51.7 & 74.3 & 53.5 & 54.1 & 68.7 & 32 & 71.3 \\
\hline Hexaporate & 3.2 & 3.1 & 6.9 & 0 & 1.9 & 2.8 & 1.5 & 9 \\
\hline \multicolumn{9}{|l|}{ Pollen wall shape (\%) } \\
\hline Concave & 34.7 & 38.8 & 22.3 & 6.8 & 64.3 & 28.0 & 34.5 & 14.8 \\
\hline Mixed & 37.4 & 37.4 & 45.7 & 59.1 & 29.8 & 51.1 & 41.1 & 43.3 \\
\hline Convex & 27.9 & 23.8 & 34.1 & 34.1 & 5.9 & 20.9 & 20.5 & 42.1 \\
\hline
\end{tabular}



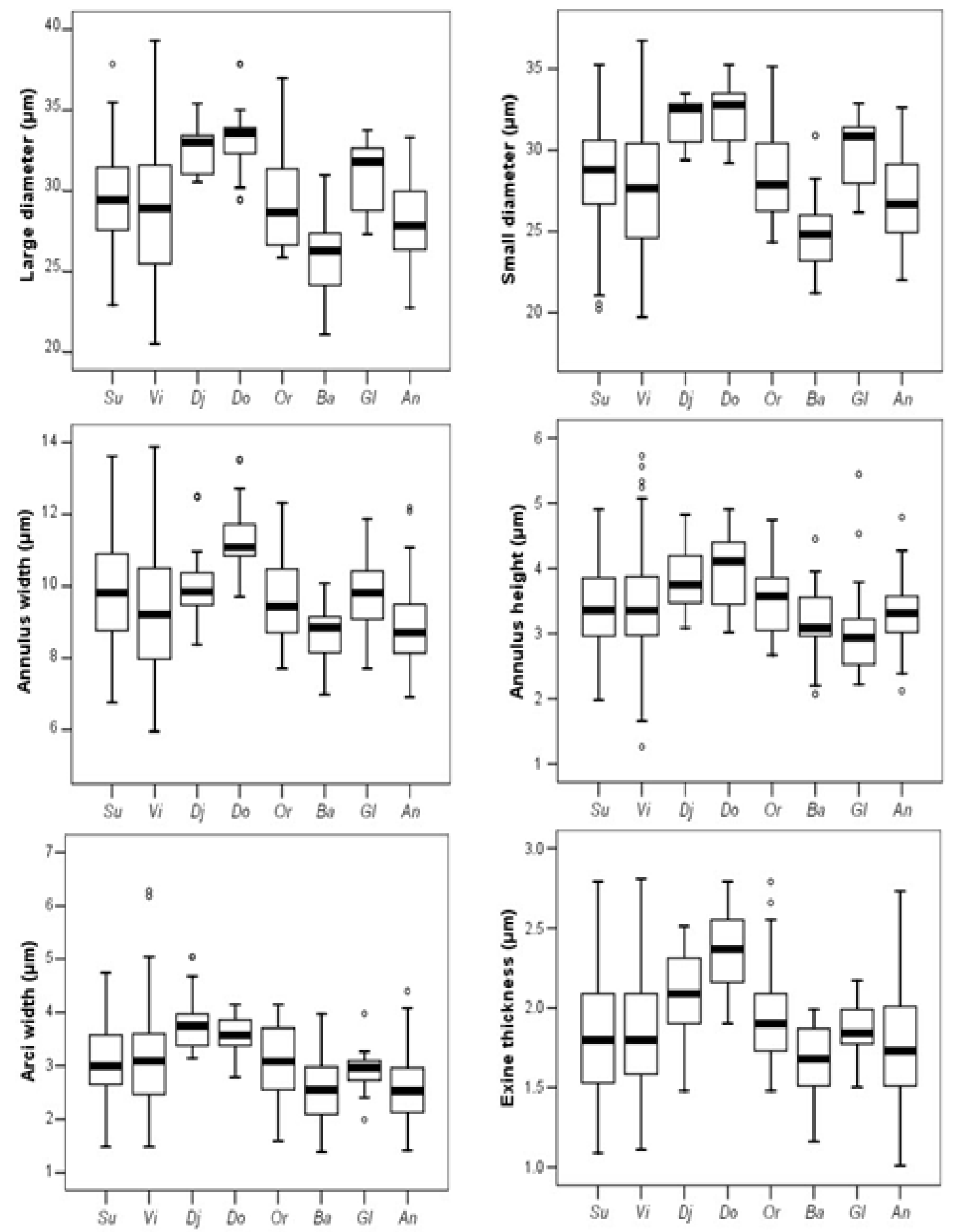

Figure 2. Box plots of six quantitative characteristics related to the eight Alnus taxa. $S u=A$. subcordata var. subcordata, $V i=A$. subcordata var. villosa, $D j=A$. Djavanshirii, $D o=A$. dolichocarpa, $\mathrm{Or}=A$. orientalis, $B a=A$. glutinosa ssp. barbata, $G l=A$. glutinosa ssp. glutinosa and $A n=A$. glutinosa ssp. antitaurica.

Figure 3 shows the light microscope photographs related to pollens of Hyrcanian alder taxa. 

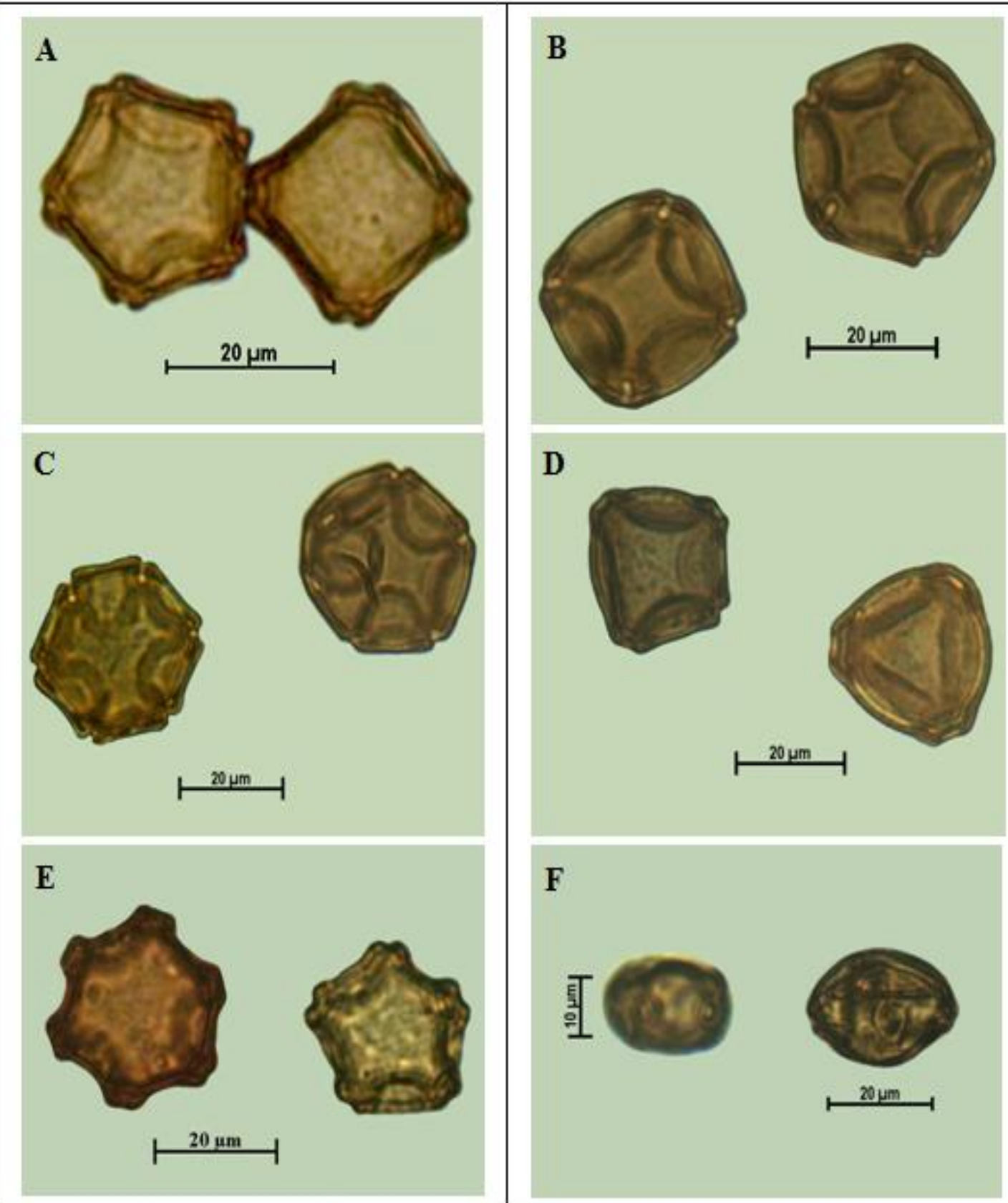

$\mathbf{F}$
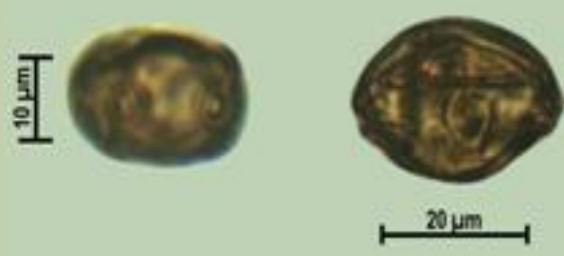

Figure 3. Images from alder pollens photographed using light microscope with a magnification of 2525x. Left to right respectively (isopolar view): A) Concave tetra- and pantoporate pollen of A. subcordata var. subcordata, B) Convex tetra- and pantoporate pollens related to A. glutinosa ssp. glutinosa, C) Convex and mixed hexaporate pollen of A. djavanshirii, D) Mixed tetraporate and convex triporate pollen of $A$. subcordata var. villosa, $E$ ) Concave panto- and hexaporate pollen of A. subcordata var. villosa, $F$ ) equatorial view of pantoporate pollen related to A. glutinosa ssp. antitaurica (left) and tetraporate pollen of A. glutinosa ssp. barbata (right).

Figure 4 and 5 also shows the SEM microscopy images of alder pollen grains from isopolar and equatorial view with the magnification of $2635 \mathrm{x}$ to $5153 \mathrm{x}$. 

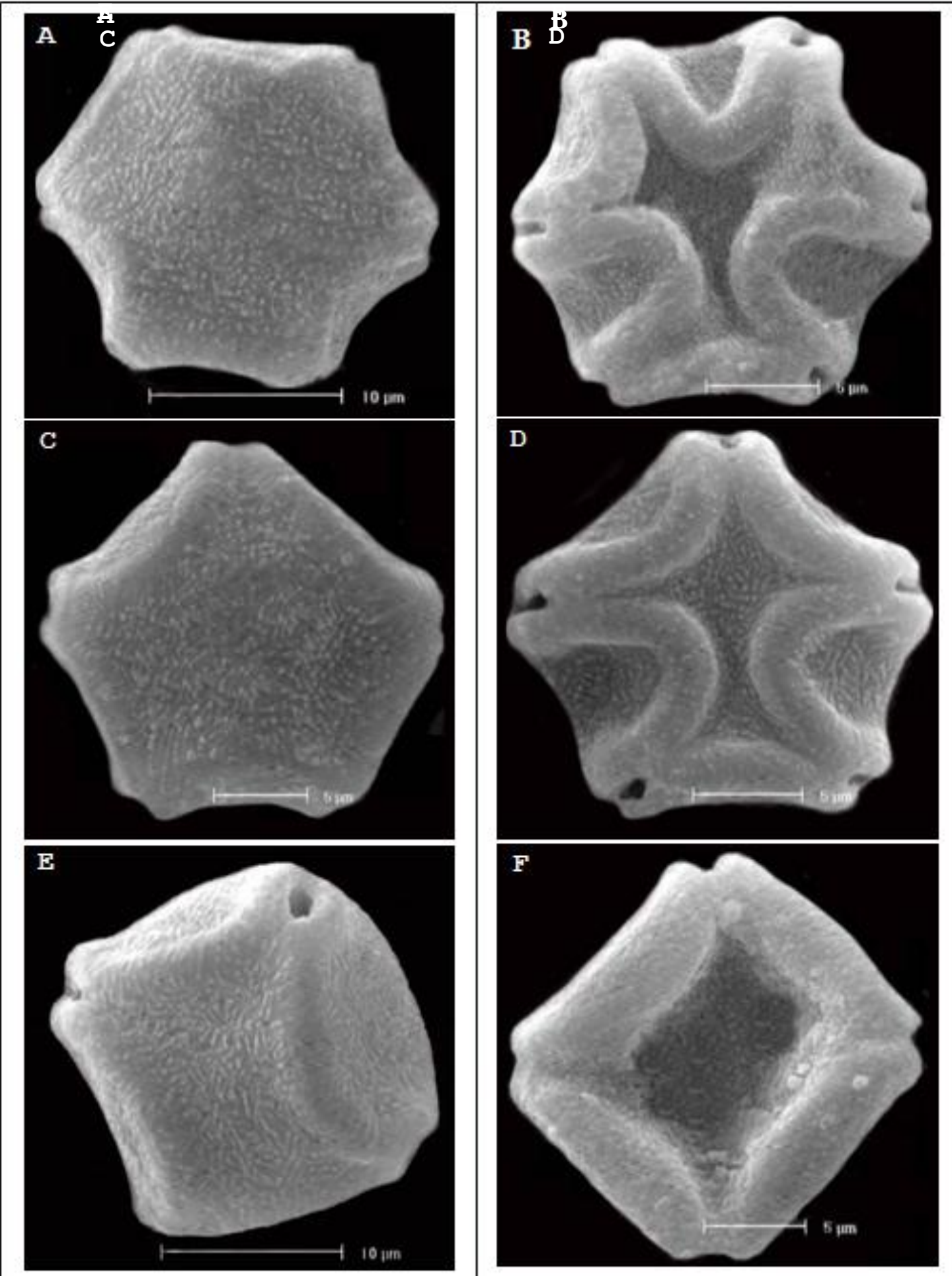

Figure 4. SEM microscopy images of alder pollens from isopolar view. A) Concave and hydrated hexaporate pollen of $A$. djavanshirii $(2635 x), B$ ) Concave and collapsed hexaporate pollen of A. glutinosa ssp. barbata (3523x), C) Concave and hydrated pantoporate pollen of A.

glutinosa ssp. antitaurica (3133x), D) Concave and collapsed pantoporate pollen of $A$.

glutinosa ssp. glutinosa (3364x), E) Mixed and hydrated tetraporate pollen of A. orientalis (2751x), F) Mixed and collapsed tetraporate pollen of A. dolichocarpa (3074x). 


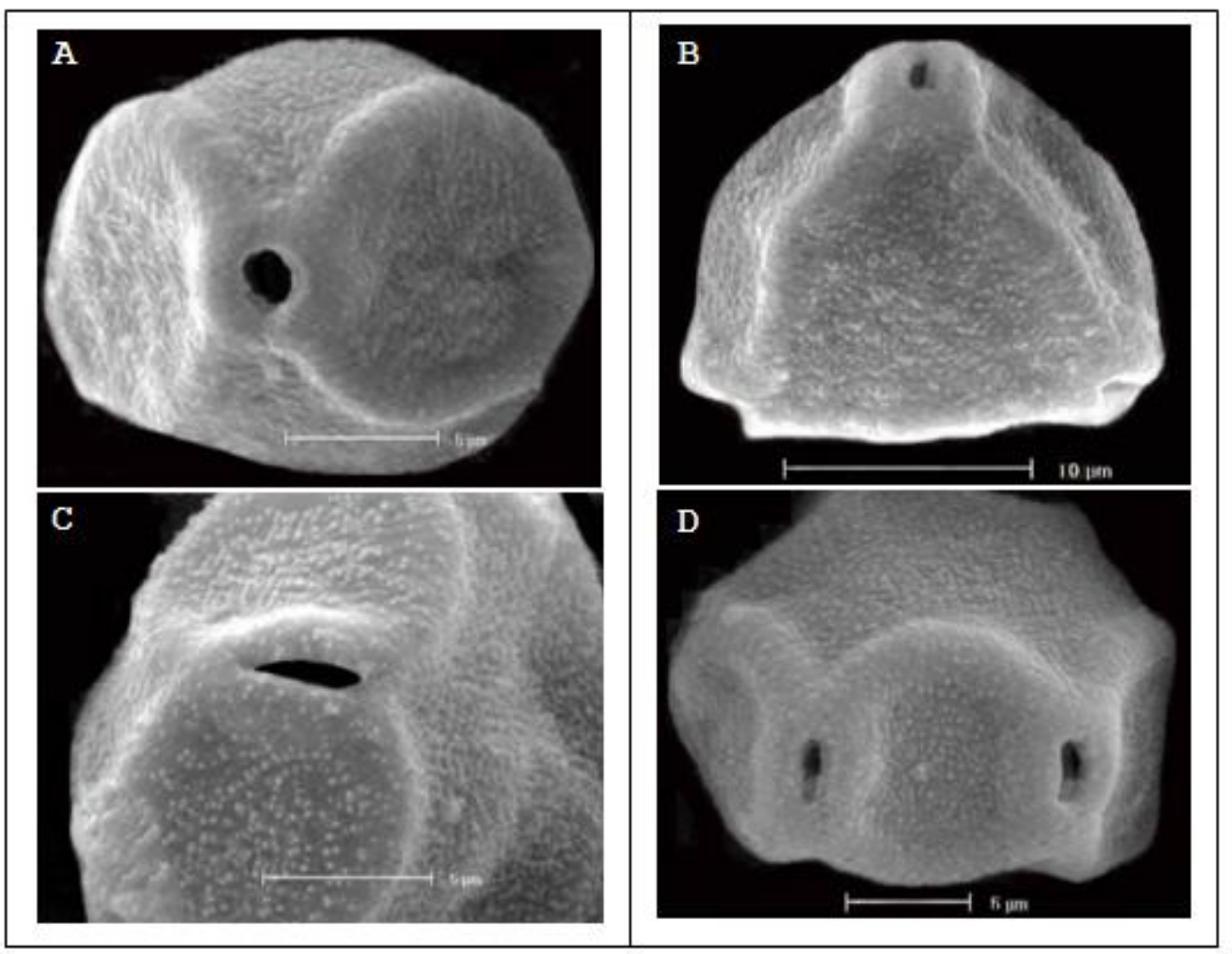

Figure 5. SEM microscopy images of alder pollen. B) Convex triporate pollen of A. glutinosa (27.56x) from oblique polar view, A) Concave tetraporate pollen of A. glutinosa ssp. glutinosa (4794x) in equatorial view, C) Concave pantoporate pollen of A. orientalis ssp. glutinosa (5153x) from equatorial view, D) Concave pantoporate pollen of A. subcordata var. villosa (3263x) in equatorial view.

Two step cluster analysis was conducted to classify Alnus taxa based on six quantitative measured traits of pollen. Figure 6 shows the results of two step cluster analysis.

As is known in Figure 6, all taxa were clustered together in a common group based on quantitative measured traits of pollen grains and no taxon has been classified in independent and distinct group.

The discriminant analysis was run based on the pollen quantitative characteristics. Table 2 listed the values canonical correlation, percentage of variance and eigenvalue parameters related to five functions determined by discriminant analysis.

Table 2. The eigenvalue, percentage of variance and canonical correlation values related to five functions determined by discriminant analysis.

\begin{tabular}{cccc}
\hline Functions & Canonical correlation & \% of variance & Eigenvalue \\
\hline 1 & 0.490 & 39.4 & 0.315 \\
2 & 0.414 & 25.9 & 0.207 \\
3 & 0.323 & 14.5 & 0.116 \\
4 & 0.276 & 10.3 & 0.083 \\
5 & 0.213 & 5.9 & 0.048 \\
\hline
\end{tabular}




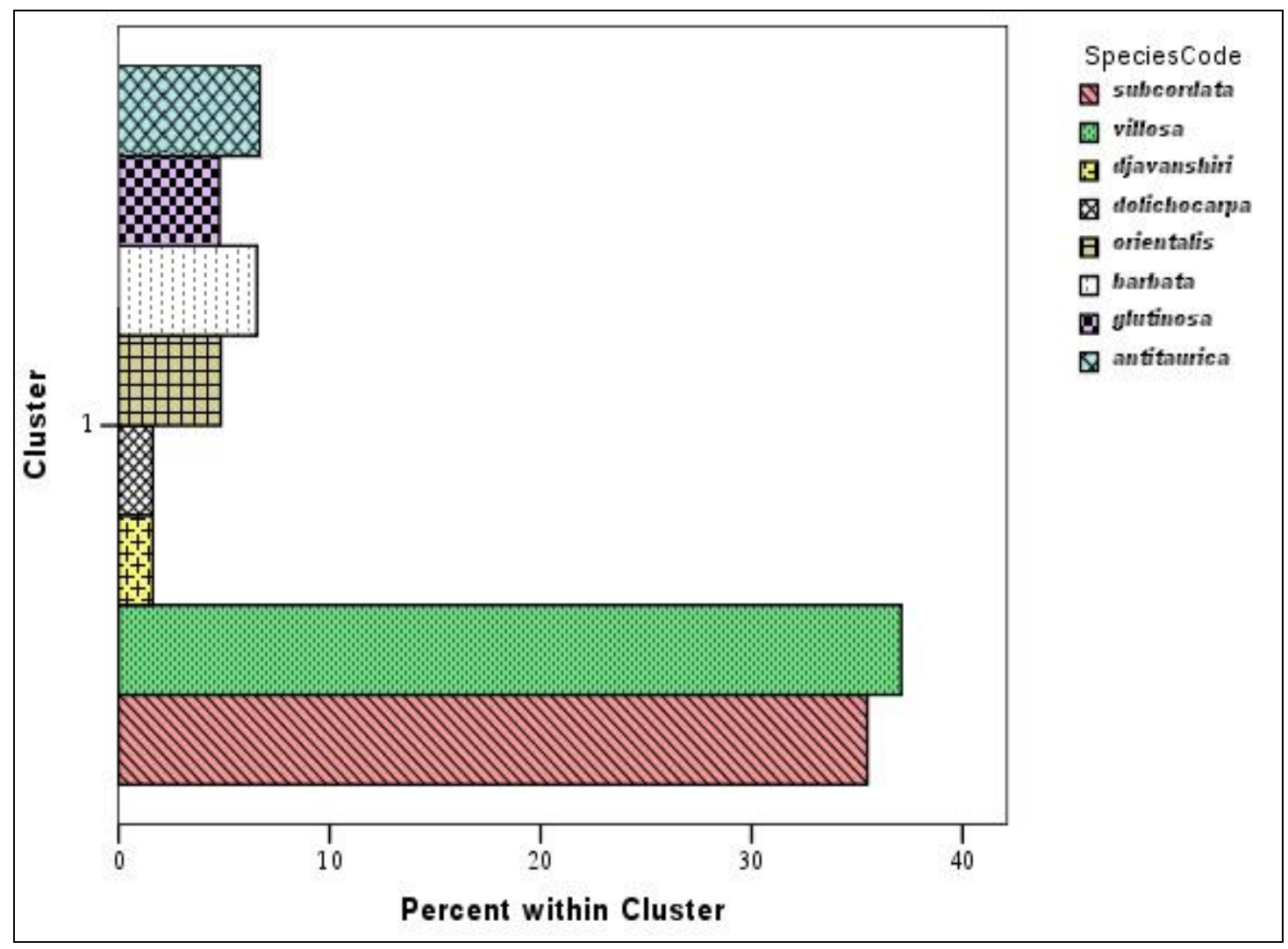

Figure 6. The result of two step cluster analysis.

As the results shown in Table 2, none of the measured characteristics were suitable to distinguish the Alnus taxa. Low eigenvalues of each of these functions is clearly assign the function is inappropriate to separate the taxa. On the other hand, only $65 \%$ of the variance is explained by the first two functions. Therefore, the six measured morphological traits associated with alder pollen can not possibly reflect the distinction between the studied taxa.

Figure 7 shows the distribution of sampled trees associated with correlation of pollen characteristics with the first two functions.

Figure 7 clearly indicates that eight taxa have shown little difference in terms of pollen morphological characteristics and consequently determining the limitation of these taxa using measured traits was not simply possible. The results of cluster analysis in consistent with discriminant analysis, indicated much similarity of Alnus taxa in the north of Iran based on pollen charactristics.

The results of Pearson correlations showed that there was a statistically significant correlation (99\% confidence level) between pollen diameter and annulus width (Sig.= $\left.0.000, r_{p}=0.743\right)$, annulus height (Sig. $\left.=0.000, r_{p}=0.346\right)$, arci width $\left(\right.$ Sig. $=0.000, r_{p}=$ 0.555 ), and pollen exine thickness (Sig. $\left.=0.000, r_{p}=0.355\right)$ whereas there was no significant correlation between pollen diameter and the number of pollen pores (Sig.= $\left.0.191, r_{p}=0.056\right)$. 


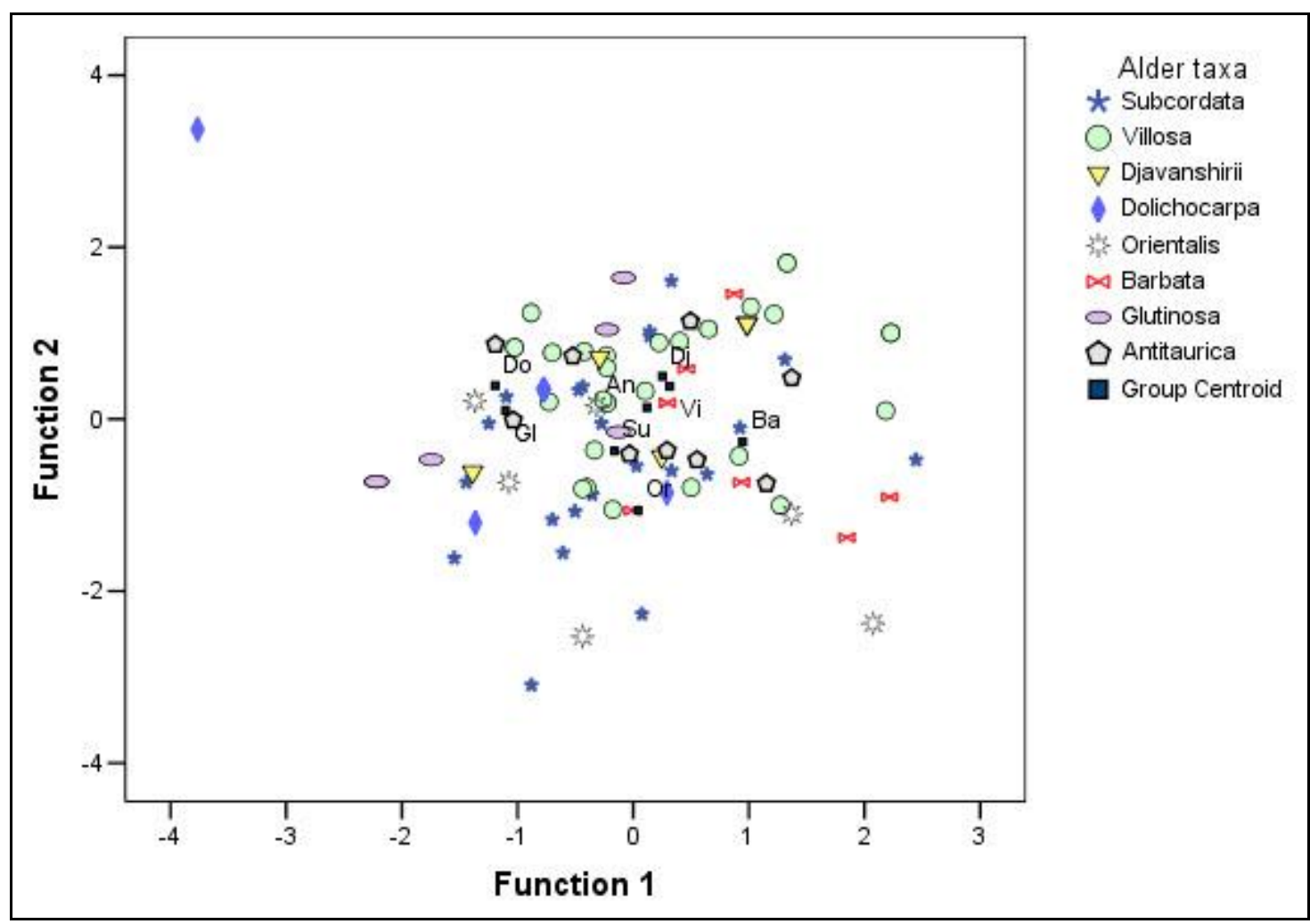

Figure 7. Distribution of sampled alder around the first and second function based on morphological analysis of the pollen

\section{Discussion}

What clearly indicated by the pollen morphological analysis of the genus Alnus was that none of the morphological traits was useful to distinguish the taxa at the species level.

The highest mean value of each pollen morphological characteristics, often observed in A. dolichocarpa and A. djavanshirii (Table 1 and Figure 2) and the least commonly was associated with $A$. glutinosa ssp. barbata and occasionally the two other subspecies namely A. glutinosa ssp. glutinosa and A. glutinosa ssp. antitaurica. In other cases, we couldn't find certain trend among taxa. Eigenvalues, percentage of explained variances and correlation between pollen traits with two functions of discriminant analysis, were very low which identification of taxa was not possible by these traits (Table 2).

The pollen type and shape, exine ornamentation and aperture type of pollens, did not reveal significant difference among eight taxa and in this respect there is no support reason in order to identify the structural differences due to evolutionary evidence in classification of the taxa.

In all taxa, tetra- and pantoporate pollens were observed. However, the latter prevailing in six taxa was the most dominant (53\% of total pollen grains), followed by tetraporate pollens ( $42 \%$ of total pollens) having the highest frequency. The hexaporate pollen was observed in all taxa except $A$. dolichocarpa. However, the triporate pollens had the lowest frequencies among the taxa; So that the triporate taxa pollen was found in three taxa. The study conducted by Reinink-Smith (2010) on the pollen fossils of the genus Alnus in Alaska, showed that pollen of this genus are often tetra- and pantoporate and tri and hexaporate grains have lower frequency. He also stated that 7-, 8- and even 
9-porate pollens are rarely observed in the genus Alnus. For example, in Alnus firma 7porate pollens are prevalent. But he also acknowledged separating and distinguishing the species based on pollen pore number, is not feasible; because presence of the specified number of pore may be similar or very close among the species. Moreover, when the number of pore in a same species is concerned, it can be expected that the greater number of pores are visible in larger grains (Reinink-Smith, 2010).

It is mentioned that the number of pores is influenced and controlled by both genetic and environmental factors (Flenley, 2003). Today, it is demonstrated that the formation of pollen grains are sensitive to specific environmental factors such as temperature and humidity, and response of plants against changes in this environmental factors are relatively fast (Dzyuba, 2006). Furthermore, the number of pores in pollens may be related to climatic factors during the growing season (Flenley, 2003). Even the position of the pollen sacs and anther on the flower and eventually flower on the tree can cause large differences in the number of pores and size of the pollen (Kurtz and Liverman, 1958; Flenley, 2003). These factors not only affect the pollen fertility, but it also affects the distribution of grains (Flenley, 2003).

Mikkelsen in 1949 demonstrated the increasing about $14^{\circ} \mathrm{C}$ temperature during the growing season can reduce the size of the pollen more than 6 percent in some species of Brassicaceae. Besides the temperature, he mentioned the importance of nutrients on the plant pollen production.

Based on the findings of this paper, larger pollen grains in the genus Alnus had greater exine thickness, arci width and annulus width. However the relationship between pollen diameter and the number of pores were not significantly differed. The study of Lee (1978) showed those pollen grains with greater number of pores, are relatively large, and they need thicker exine to keep the grain structure. Mulcahy (1974) also acknowledged larger pollen need to have more number of pores in order to absorb enough water from the stigma with the rate of smaller grains. Rapid absorption of water is a selective advantage because it allows the development of pollen tubes with higher rate and eventually faster fertility. Therefore, larger pollen grains with more number of pores can better compensate the need of water absorption (Lee, 1978).

Proportion of pollen shape (wall type) which was divided into three types of concave, convex and mixed pollen was almost similar in all Alnus taxa and cannot be stated that each of these types are unique to specific taxon; it was also similar about the number of pores per pollen, as mentioned before.

SEM microscopy results also did not show difference in the type of exine ornamentation in all taxa (Figure 4 and 5).

Results of classification by two-step cluster analysis and discriminant analysis clearly indicated that the morphological characteristics of pollen in the genus Alnus cannot even distinguish one taxon from other taxa; Since the population of individuals in each taxon are mixed completely within other taxa, and certain limits can not be identified to separate them (Figure 7).

Totally, based on the whole results of the study using light and electron microscopy in this paper, should be noted that pollen related characteristics in the genus Alnus can not resolve the taxonomical and systematical problems of the genus; The main reason for this can be slight variation of pollen characteristics in terms of structural properties of pollen and quantitative traits. However, in many cases, the pollen types and its attributes has been largely used in the classification of plants (Wen and Nowicke, 1999; Lin et al., 2005; Aktaş et al., 2010; Liu et al., 2011; Doyle and Thomas, 2012;). The 
pollen analysis of the genus Picea was very useful for distinguishing species in North America (Lindbladh et al., 2002). In some genera of plants, the results of pollen analysis was in agreement with molecular studies (Wen and Nowicke, 1999).

However, the results of another study conducted on three species of alder in the U.S. showed similar results with our study. May and Lacourse (2012) stated that pollen characteristics are not suitable for distinguishing three taxa of A. rubra, A. incana subsp. tenuifolia and A. viridis subsp. sinuate and despite significant differences in the characteristics of these taxa decision can not be made for separating at the species level, due to high degree of overlap in the characteristics of the taxa.

\section{Conclusion}

According to the results of this paper, pollen characteristics were not found suitable to separate the Alnus taxa. Also the five new taxa recently added to the floristic list of Hyrcanian Alders of Iran (Zare and Amini, 2012) did not show significant differences with other taxa based on pollen characteristics. The classification of these taxa, two of which have been introduced as new species to the world list of Alnus for the first time (A. dolichocarpa and A. djavanshirii), still needs to be further tested using DNA barcoding techniques and other genetic methods. However, the non-discrimination (unseparability) of Alnus taxa, based on pollen analysis, is related to the very little variations in the type and other traits of pollen in this genus.

\section{REFERENCES}

[1] Aguilar-García, S.A., Figueroa-Castro, D.M., Castañeda-Posadas, C. (2012): Pollen morphology of Pachycereus weberi (Cactaceae): an evaluation of variation in pollen size. - Plant Systematics and Evolution 298: 1845-1850.

[2] Aktaş, K., Altan, Y., Özdemir, C., Baran, P., Garnatje, T. (2010): Comparative pollen morphology of Turkish species of Petrorhagia (Caryophyllaceae) and its systematic implications. - Biologia 65(3): 444-450.

[3] Ashburner, K. (1986): Alnus: a survey. - Plantsman 8:170-188.

[4] Blackmore, S., Steinmann, J.A.J., Hoen, P.P., Punt, W. (2003): The northwest European pollen flora, 65, Betulaceae and Corylaceae. - Review of Palaeobotany and Palynology 123: 71-98.

[5] Browičz, K. (1972): Betulaceae in K. H. Rechinger (ed.). - Graz, Flora Iranica no: 96.

[6] Chen, Z., Li, J. (2004): Phylogenetics and biogeography of Alnus (Betulaceae) inferred from sequences of nuclear ribosomal DNA region. - International Journal of Plant Sciences 165(2): 325-335.

[7] Chen, Z.D., Manchester, S.R., Sun, H.Y. (1999): Phylogeny and evolution of the Betulaceae as inferred from DNA sequences, morphology and paleobotany. - American Journal of Botany 86: 1168-1181.

[8] Chen, S.L., Yao, H., Han, J.P., Liu, C., Song, J.Y., Shi, L.C., Zhu, Y.J., Ma, X.Y., Gao, T., Pang, X.H., Luo, K., Li, Y., Li, X.W., Jia, X.C., Lin, Y.L., Leon, C. (2010): Validation of the ITS2 region as a novel DNA barcode for identifying medicinal plant species. - PLoS One, 5: e8613.

[9] Chung, K.S., Elisens, W.J., Skvarla, J.J. (2010): Pollen morphology and its phylogenetic significance in tribe Sanguisorbeae (Rosaceae). - Plant Systematics and Evolution 285: 139-148.

[10] Doyle, J.A., Thomas, A.L. (2012): Evolution and phylogenetic significance in Annonaceae. - Botanical Journal of the Linnean Society 169: 190-221. 
[11] Dzyuba, O.F. (2006): Pollen from surface samples as an environmental indicator. Paleontological Journal 40: 584-489.

[12] Erdtman, G. (1960): The Acetolysis Method. A revised description. - Svensk Bot. Tidskr. 51: 561-564.

[13] Erdtman, G. (1986): Pollen morphology and plant taxonomy: Angiosperms (An introduction to pollen analysis). - Brill E.J. (ed.), Leiden, The Netherlands.

[14] Flenley, J. (2003): Some prospects for lake sediment analysis in the 21st century. Quaternary International 105: 77-80.

[15] Furlow, J.J. (1979): The systematics of the American species of Alnus (Betulaceae). Rhodora 81: 1-121, 151-248.

[16] Hesse, M., Halbritter, H., Zetter, R., Weber, M., Buchner, R., Frosch-Radivo, A., Ulrich, S. (2009): Pollen Terminology An illustrated handbook. - SpringerWienNewYork, University of Vienna, Austria, Printed in Austria, 261 p.

[17] Hong, S.P. (2007): Pollen Morphology and Its Systematic Implications for the Genera Keiskea Miq. and Collinsonia L. (Elsholtzieae-Lamiaceae). - Journal of Plant Biology 50(5): 533-539.

[18] King, R.A., Ferris, C. (2000): Chloroplast DNA and nuclear DNA variation in the sympatric alder species, Alnus cordata (Lois.) Duby and A. glutinosa (L.) Gaertn. Biological Journal of the Linnean Society 70: 147-160.

[19] Kurtz, E.B., Liverman, J.L. (1958): Some effects on temperature on pollen characters. Bulletin of the Torrey Botanical Club 85: 136-138.

[20] Lee, S. (1978) A factor analysis study of the functional significance of angiosperm pollen. - Systematic Botany 3: 1-19.

[21] Lin, J., Qin, W., Liu-zhong, Y., You-run, L. (2005): Pollen morphology of Artemisia L. and its systematic significance. - Wuhan University Journal of Natural Sciences 10(2): 448-454.

[22] Lindbladh, M., O'Connor, R., Jacobson, G.L. (2002): Morphometric analysis of pollen grains for paleoecologica studies: Classification of Picea from eastern North America. American Journal of Botany 89(9): 1459-1467.

[23] Liu, J.X., Zhao, C.H., Liu, X.R., Xi, Y.Z., Zhang, Y.L. (2011): Pollen morphology of Hosta Tratt. in China and its taxonomic significance. - Plant Systematics and Evolution 294: 99-107.

[24] Lopes, R.C., Andreata, R.H.P., Cartaxo-Pinto, S., Trovó, M., Gonçalves-Esteves, V. (2013): Pollen morphology and wall structure of Neotropical species of Herreria and Clara (Asparagaceae-Agavoideae) and its taxonomic implications. - Plant Systematics and Evolution 299: 25-34.

[25] May, L., Lacourse, T. (2012): Morphological differentiation of Alnus (alder) pollen from western North America. - Review of Palaeobotany and Palynology 180: 15-24.

[26] Mikkelsen, V.M. (1949): Has temperature any influence on pollen size? - Physiologia Plantarum 2: 323-324.

[27] Mulcahy, D.L. (1974): Correlation between speed of pollen tube growth and seedling height in Zea mays L. - Nature 249: 491-493.

[28] Murai, S. (1964): Phytotaxonomical and geobotanical studies on gen. Alnus in Japan. III. Taxonomy of whole world species and distribution of each sect. - Bull. Gov. For. Exp. Stn. Jpn. 171: 1-107.

[29] Reinink-Smith, L.M. (2010): Variations in alder pollen pore numbers - a possible new correlation tool for the Neogene Kenai lowland, Alaska. - Palynology 34(2): 180-194.

[30] Ren, B.Q., Xiang, X.G., Chen, Z.D. (2010): Species identification of Alnus (Betulaceae) using nrDNA and cpDNAgeneticmarkers. - Molecular Ecology Resources 10: 594-605.

[31] Rieseberg, L.H., Brouillet, L. (1994): Are many plant species paraphyletic? - Taxon 43: 21-32.

[32] The Plant List, (2010): Version 1. Retrieved from http://www.theplantlist.org/ on: 17 March 2013). 
[33] Wen, J., Nowicke, J.W. (1999): Pollen ultrastructure of Panax (the ginseng genus, Araliaceae), an eastern Asian and Eastern North American disjunct genus. - American Journal of Botany 86(11): 1624-1636.

[34] Zare, H., Amini, T. (2012): A review of the genus Alnus Mill. in Iran, New records and new species. - Iranian Journal of Botany 18(1): 11-21. 